\title{
Examination of Mummies from the Tomb of lufaa at Abusir (Egypt)
}

Eugen Strouhal

Institute for the History of Medicine, First Medical Faculty,

Charles University, Katefiinská 32, I2I 08 Prague, Czech Republic

KEY WORDS: identification, relationship, blood groups, pathology

\section{Abstract \\ The 1998-2004 investigation of the tomb of lufaa at Abusir (before 625 BC) by the Czech Institute of Egyptology, uncovered the burials of five adults. All were mummified and excerebrated, but the high humidity in the tomb disintegrated the mummy wrappings and soft tissues. The skeletons were saved using disinfectant and consolidating means. Three individuals were found to be morphologically and genetically closely related using descriptive, metric and epigenetic methods: The priest Iufaa, Lady Imakhetkherresnet and an anonymous male. The first two were siblings, as confirmed by epigraphic references to the same mother. Two others were priests, Neko and Gemenefherbak, whose skeletons survived partially. Their epigenetic features could be studied showing a similarity of $75 \%$. Several pathological features were identified such as a benign neurilemmoma in a sacrum diagnosed for the first time in paleopathology.}

\section{Introduction}

Czech Institute of Egyptology, Charles University Prague, started investigation of one of the big shaft tombs located half $\mathrm{km}$ south of the pyramid of Neferirkare at Abusir in 1994. The fact that the tomb was found undisturbed by robbers attracted attention of the public. According to its great dimensions, architectural shape and found burial equipment, the tomb has been dated to the end of 26th (Saitic) Dynasty, before year 525 BC.

\section{Material}

Up-to-date, when investigation of the tomb has been concluded, it yielded mummies of 5 persons which we present in chronological order of their discovery (Fig.1, nos.1-5).

(1) At the bottom of the main square shaft in the depth of $24 \mathrm{~m}$, a burial chamber was built of big stone blocks. It was found occupied by a huge rectangular limestone sarcophagus, which was opened in 1998. In it a second, anthropomorphic basalt sarcophagus was placed. It contained remains of a decayed anthropomorphic wooden coffin protecting a mummy of priest lufaa (further: IU),

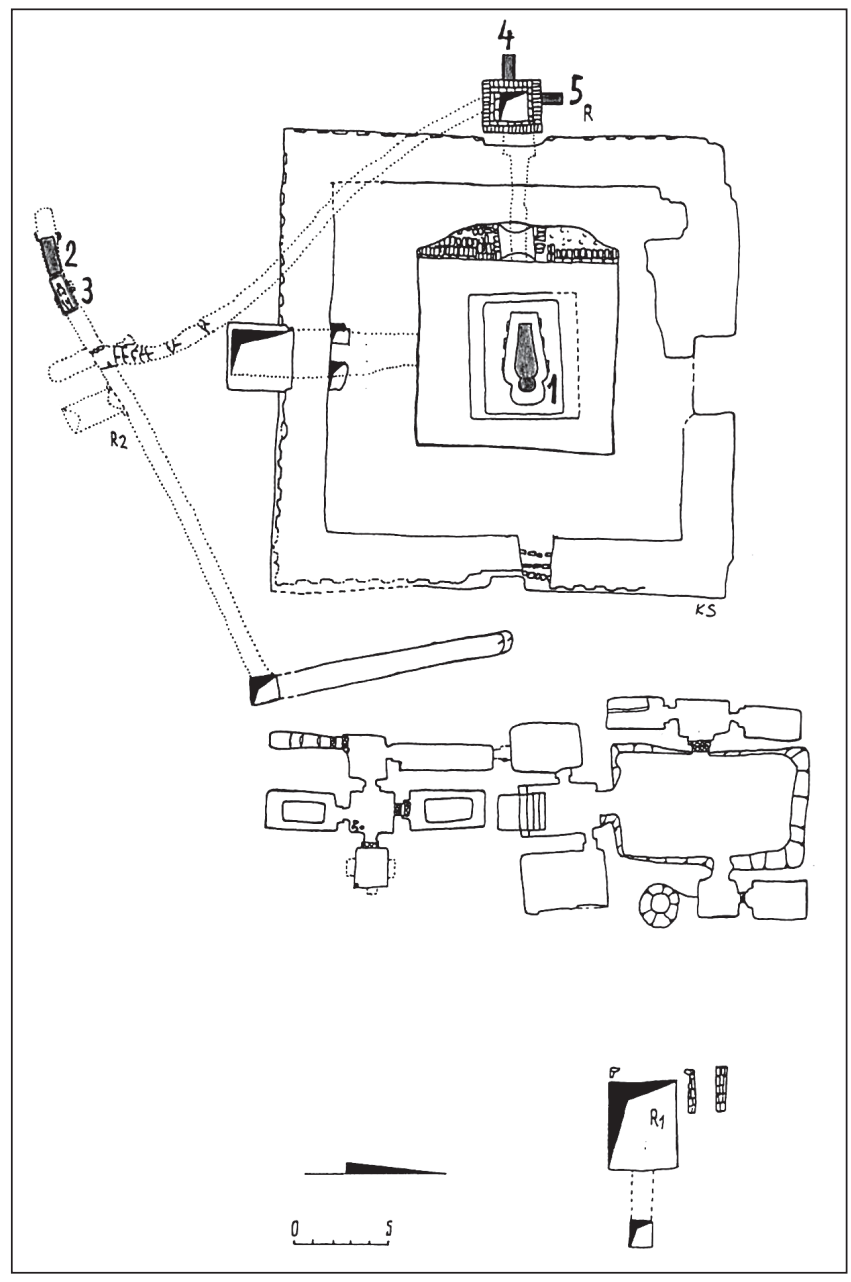

Fig. 1 - Schematic plan of the Shaft Tomb of lufaa. Burials of single persons are numbered: I lufaa, 2 Imakhetkherresnet, 3 anonymous male, 4 Neko, 5 Gemenefherbak. Drawing: K. Smoláriková. 
«administrator of palaces», adorned by a beautiful bead net (Bare? and Strouhal 2000).

(2) At the western dead end of a corridor south of lufaa's tomb, connected by a S-shaped descending passage with the bottom of its west auxilliary shaft, mummy of a woman Imakhetkherresnet (IM) was found in a double rectangular wooden coffin.

(3) Another mummy of an anonymous male (further:AN) lay in front of it amidst remains of a decayed wooden coffin and burial equipment. Both mummies were investigated in 200I (Bareš et al., 2002).

(4) Two other mummies were found in additionally excavated niches in the west shaft of lufaa's tomb. One of them was the "God father» Neko (further: NK) buried in its west wall in autumn 2003; Bare? et al., in press.

(5) He was followed by another priest and «administrator of palaces» Gemenefherbak (further: GE) whose burial was inserted into the north wall, higher than the previous one. His remains were discovered in spring 2004 (Bareš et al., in press).

\section{Preservation of the mummies}

All persons were mummified as evidenced by wrappings permeated by resin, black stains on the bones and brain removal with resinous filling of the posterior thirds to half of the braincases. Unfortunately, applied coating of the wrappings by resin was not thick and continuous enough to isolate the dessicated bodies against the moisture. Relative humidity inside the tomb is $85-90 \%$ with temperature of $26-28^{\circ}$, in the southern corridor only slightly less. Already during their lifting and $X$-raying the mummies were found to be infected by moulds, and by influence of dry air they began to break into parts (Fig. 2).

By removing the disintegrating wrappings, the skeletons or their parts were saved. During this operation, about 20 amulets and 20 gilded cases for fingers and toes were found in the mummy of IU and several of them also in the other ones. The extracted bones were cleaned mechanically and spread by antimycotic solution Betadin. Later they were treated by consolidant Paraloid B-72. Preservation of the skeletons was best in IM, IU and AN, partial in NK and only fragmentary in GE, where even diaphyses of some long bones perished, leaving in situ only their wrappings.

\section{Demographic data of the individuals}

(1) IU's skeleton is medium robust with less developed muscular relief in the upper extremities compared with the more muscular lower ones. Secondary sexual features attest male sex. Stature reconstructed by tables for Afroamericans (Trotter and Gleser 1952), whose proportions better suit to those of the Ancient Egyptians, was $170.1 \mathrm{~cm}$.

In spite of a number of pathological changes, age at death determined after split of the freshly fused ossification fissures of the cristae iliacae and the ascending ramus of

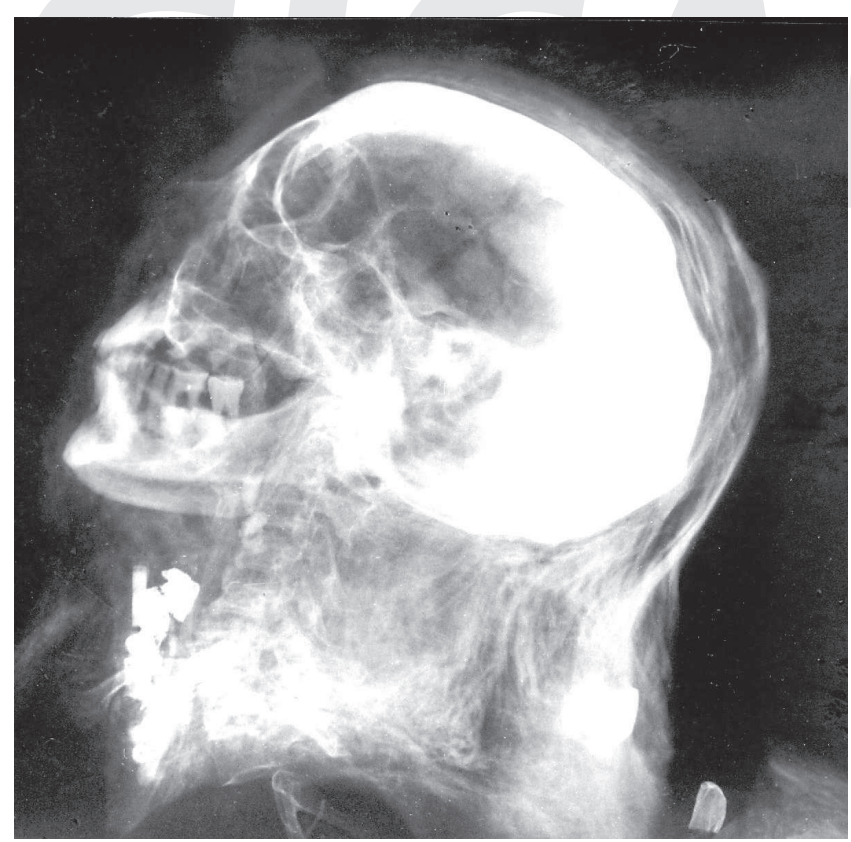

Fig. 2 - Lateral standard X-ray of the head and neck of lufaa. Posterior third of the braincase is obscured by resinous filling. A dish-shaped depression was caused by biparietal thinness. Upper premolars and molars were lost infra vitam. Contrast shadows at neck mark amulets and beads, a less contrast one at the rear gilded case for tip of a finger. $X$-ray: Mohammad al-Tohany.

the left pubis, as well as by the peeled off head of the left femur - all caused by abrupt dessication of the skeleton point to young adult age. This agrees well with the wiped off relief of facies symphysialis of the pubis (stage 4 by Todd 1920 ) and the still youngish surfaces of the facies auriculares of the sacrum and ilia (Lovejoy et al., 1985). The proposed age of 25-30 years has been supported by microscopic investigation of the mid-section of 7 th left rib. It showed that its compact bone retained a substantial share of the lamellar bone which was not yet fully substituted by osteons (Saunders 2003).

(2) IM's skeleton is gracile with a relatively well developed muscular relief. Secondary sexual features are clearly of a female. Her stature was $151.5 \mathrm{~cm}$.

Age at death was determined by progressed fusion of cranial sutures, facies symphysialis of stage 8 , incipient degenerative arthritis of big joints and medium stage of osteophytosis of the spine into the range of 35-45 years. (3) AN's secondary sexual features are of a male except for the broadly open incisura ischiadica major. His skeleton shows feeble robusticity. Preserved relief of muscular insertions betrays, however, the originally strongly developed musculature. His stature was $159.4 \mathrm{~cm}$. Age at death could be determined according to almost completely fused cranial sutures, senile changes of the facies auriculares, general osteoporosis up to senile atrophy (in scapulae and ilia) as well as progressed degenerative arthritis of big joints and osteophytosis of the spine into the range of 55-65 years.

(4) NK's skeleton clearly reveals male features but a gracile body build (especially of the arms and the rib cage).

Muscular relief is feeble in the upper extremities, stronger 
in the lower ones. His stature was $166.6 \mathrm{~cm}$.

Bones are well mineralized, arthritic changes only begin, osteophytosis of the spine is medium progressed.

Ossification of the thyreoid cartilage of stage 6 (Vlãek 1974) and facies symphysialis of stage 7 attest age at death in the range of $35-45$ years.

(5) The almost destroyed mummy of GE preserved a few male secondary sexual features. But his body build is gracile and the muscular relief feeble (also on the leg bones). The stature was assessed by comparison either of the length of his preserved spinal section $T_{3}-L_{5}$, or of the reconstructed length of his spine with identical measurements of NK's spine as only $155.4 \mathrm{~cm}$ or $157.3 \mathrm{~cm}$ respectively (according to Fully and Pineau 1965).

Concerning his age at death, cranial sutures are in fusion, facies symphysialis shows stage 7 , osteophytosis of the spine is medium. The range of $35-45$ years appears most probable.

\section{Morphological detection of blood relationship}

Well preserved skeletons of IU, IM and AN were compared by method of mean distance between their pairs (STROUHAL, 2002). It was calculated as square root from the sum of powers of differences between pairs of used measurements divided by their number.

Cranial measurements were analyzed (I) not only as a whole $(n=22)$, but also divided into (2) the neurocranic ones together plus the bizygomatic breadth $(n=9)$ and (3) the remaining facial dimensions $(n=\mid 3$; Fig.3, left part).

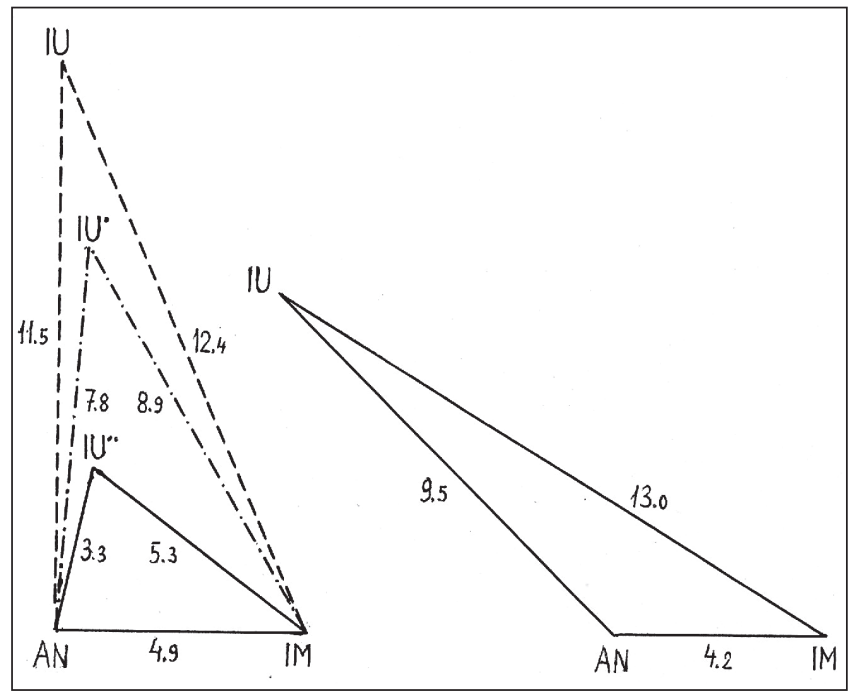

Fig. 3 - Mean morphological distance (in $\mathrm{mm}$ ) between the three well preserved persons: $I U=$ lufaa, $A N=$ anonymous male, $I M=$ Imakhetkherresnet. Left: ___ = facial measurements, - - - - = neurocranial measurements, -.-.-. = all cranial measurements. Right: mandibular measurements. Drawing: E.Strouhal.

The mean distance between IM and AN appears identical in all these three groups of measurements $(4.8-5 \mathrm{~mm})$. They differ only by the elongated braincase in $\mathrm{AN}$ and the spheric short one in IM, as well as by the high narrow face in $\mathrm{AN}$ and the lower and broader one in IM. IU resembles both of them in the facial dimensions (except breadth), more AN (3.3 mm) than IM (5.3 mm, Fig.4).

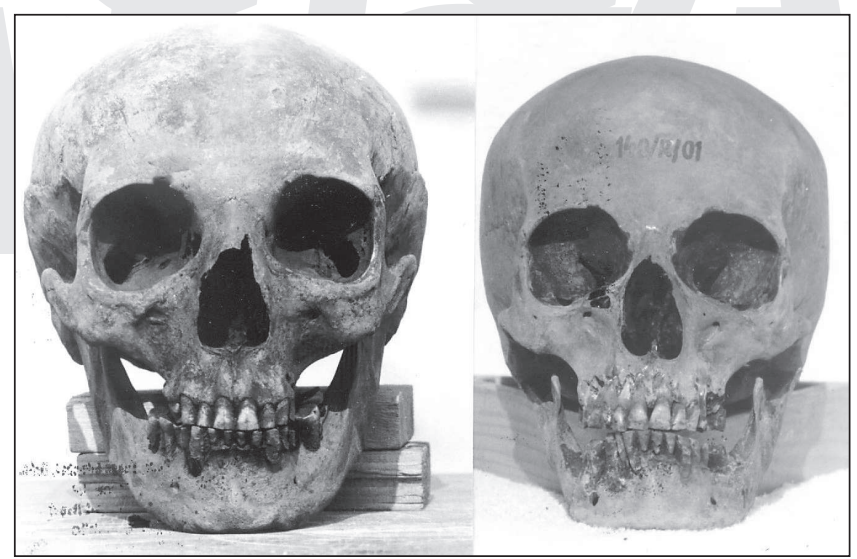

Fig. 4 - Comparison of facial views of lufaa and his sister Imakhetkherresnet. Photographs: E.Strouhal.

In the neurocranic measurements (plus bizygomaticl breadth), the distances of IU to AN (I I.5 mm) and IM (I 2.4 $\mathrm{mm})$ are three or two-and-half times, respectively, bigger. This is caused by IU's unusual platycrany (a very low and broad neurocranium), correlated with a broad face and a wide interorbital breadth. This could had been probably a congenital anomaly connected with the premature fusion of his cranial sutures.

If all used dimensions were compared together, the distances between IU and AN $(7.8 \mathrm{~mm})$ as well as between $\mathrm{IU}$ and IM $(8.9 \mathrm{~mm})$ lie between the neurocranic and facial measurements.

On the other hand, the mandibular measurements $(n=8$; Fig. 3, right) show again the close proximity of AN and IM (distance of $4.2 \mathrm{~mm}$ only) in spite of their different sex. IU stands closer to male AN $(9.5 \mathrm{~mm})$ than to female IM (I 3 $\mathrm{mm})$.

Also comparing 16 craniological indices, only 5 proved to be different in the three persons. Other 4 are similar in $A N$ and $I M, 3$ in IU and IM, 2 in IU and AN, one is closely similar in all three individuals and one is practically the same in all of them (transversal frontoparietal index). From 6 angles of the vertical facial profile 5 are similar in all three persons, only the zygomatic one differs according to their age and sex. Proximity of these three persons is expressed in their cranioscopic features, as the concave nasal bridge, the fluent nasofrontal transition, the feeble glabella and arcus superciliaris, the rhombic orbits with round angles, the medium developed spina nasalis anterior, the feeble lineae temporales, the feeble to medium cristae mastoideae, the feeble protuberantia occipital externa, the expressive sulcus sagittalis and the medium developed occipital muscular relief.

\section{Genetic and epigenetic evidence of relationship}

Biparietal thinness caused deep depressions in IU (Fig.2), shallow ones in $\mathrm{AN}$. Its frequency is O.4-I.3\% (Bretinger, 
1982). It was considered traditionally senile atrophy but according to more recent investigations it is most probably a congenital anomaly (Hauser and De Stefano, 1994).

Both IU and IM showed cranial variation of their spines in which the transitory vertebra between the thoracic and lumbar sections is $T_{1} \mid$ instead of the usual $T_{12}$. In the same time, vertebra $L_{5}$ is sacralized, consisting of 6 instead of 5 vertebrae. This variation can be found in $4.2 \%$ of sacra (âihák, 200I). Sacra of both IU and IM resemble also in shape especially the enlarged anterior slopes towards third sacral apertures.

On the right side of the posterior arch of the atlas of AN and IM, an anomalous tiny opening is apparent, whose thorns can be found also in left side of AN and in the right side of IU.

Also epigenetic features of the skull (Velemínsk?, 1999) of the three mentioned persons $(n=52-61)$ were in $80 \%$ identical and in 4-9\% of similar. Of 20 assorted postcranial epigenetic features $60-65 \%$ were identical or closely similar. According to these results all three persons appear clearly blood related. IU and IM (Fig.4) proved to be siblings also by epigraphic evidence of their most probably identical mother Ankhtisi. The old male AN could had been, with regard to timing of its burial soon after the death of IM, and the 20-year difference between their ages at death, more probably the father of IM and IU than their older brother.

\section{Relation of Neko and Gememenefherbak to other persons}

Remains of two further individuals, due to their bad preservation, were not suitable to be compared with the above mentioned three blood related persons by the same method.

Only the NK's preserved facial profile curve from nasal bridge to forehead resembles the same curves of IU and AN.

Also NK and GE possess six-piece sacra which, however, originated by fusion of the sacral vertebrae with the first coccygeal vertebra, an expression of the caudal spinal variation. To ascertain position of $\mathrm{NK}$ and GE in relation to the three related persons, 35 epigenetic features ( 14 cranial and 21 postcranial ones), were selected. They had to be preserved at least in one pair of them and their frequency should not be zero. While IU and AN show $66.1 \%$ of these features identical, AN and IM 69.4\% and IU and IM 73.5\%, NK and GE share $73.7 \%$ of features, almost exactly as much as the previous siblings.

In the same time NK resembles in the same features IM only in $30.9 \%$, and IU in $40.0 \%$ features, but $\mathrm{AN}$ in $53.3 \%$. Similarly GE resembles IM only in $27.5 \%$, IU in $35.0 \%$, but AN in $58.8 \%$ features.

In spite of the limited number of preserved features we may suggest a working hypothesis that relation existed between NK and GE. They could have been brothers. A less expressed relation cannot be excluded also between each of them and AN. We may conjecture that both could have been sons of AN and his another wife. On the NK's coffin his mother's name Irturut survived. Mother's name of GE unfortunately perished with his coffin.

\section{Blood group properties}

Determination of the blood group properties was performed from bone tissue by the saturation method, controlled by the absorption-elution method in the first three persons (Klír, 2004).

The three persons determined morphologically as blood related (IU,AN and IM) shared the same group A. Identical group A was found also in NK. In distinction to all others, GE proved to possess group $B$.

In spite of it GE could have been brother of NK if Irturut, mother of NK and presumably of GE, possessed group $B$ or $A B$ and their father was $A N$.

\section{Palaeopathology}

Among several palaeopathological findings in bones of the five mentioned persons were congenital anomalies (IU, IM, $A N)$, osteophytosis of the spine (all), osteoporosis (IU,AN), mild or progressed degenerative arthritis (IM,AN, NK), well healed spiral fracture of the right crural bones (IM) and a benign tumour neurilemmoma (IM; Strouhal et al., 2003). Among tooth diseases caries, dental attrition, sequelae of both and periodontal disease were found in all persons (except for GE with only 4 survived isolated teeth).

The most interesting case is a rare find of a sacral neurilemmoma of IM (see Strouhal and Nûmeãková, 2004). This solid benign tumour originating in a nerve sheath excavated by pressure a large three-lobulated cavity inside the sacrum. The right half of $\mathrm{S}_{2}$ segment became gradually perforated by a large smooth orifice through which the tumourous mass grew outside probably in an hour-glass shape. IM experienced increasing pains in the pelvic region and legs. Ultimately she could have been even paraplegic. The diagnosis of the tumour was determined according to its gross morphology and histology as a neurilemmoma or schwannoma. This is the first case of this rarely occurring tumour revealed in palaeopathology.

\section{Literature Cited}

Bare L, Dvofiák M, Smoláríková K, and Strouhal E. 2002. The Shafttomb of lufaa at Abusir in 200I. Zeitschr Ägypt Sprache Altertumsk 129:97-108.

Bare L, Dvofiák M, Smoláríková K, and Strouhal E, in press. The Saitic-Persian Cemetery at Abusir in 2003-04. Zeitschr Ägypt Sprache Altertumsk.

Bare L, and Strouhal E. 2000. The Shaft-tomb of lufaa - season of 1997/98. Zeitschr Ägypt Sprache Altertumsk 127:5-14.

Barnes E. 1994. Developmental defects of the axial skeleton in paleopathology. Niwot, Colorado. Univ. Press of Colorado.

Breitinger E. 1982. Depressio biparietalis circumscripta I.Archäol Austriaca 66:141-153.

Âihák R. 200I.Anatomie I. 2nd edit. Praha: Grada. 
Fully G, and Pineau H. 1965. Determination de la stature au moyen du squelette. Annal Médec légale 40:I45-153.

Hauser G, and De Stefano GF. 1989. Epigenetic variants of the human skeleton. Stuttgart: Schweizerbart.

Klír P. 2004. Personal communication of June 6, 2004.

Lovejoy CO, Meindl RSW, Prybeck TR, and Mensforth R. 1985. Chronological metamorphosis of the auricular surface of the ilium. Amer J Phys Anthrop 68:15-28.

Saunders S. 2003. E-mail of February 5, 2003.

Strouhal E. 2002. Relation of lufaa to persons found beside his Shaft-tomb at Abusir (Egypt). Anthropologie 40:37-50.

Strouhal E, and Nûmeãková A. 2004. Paleopathological find of a sacral neurilemmona from Ancient Egypt.Amer J Phys Anthrop 125/4: 320-328.

Strouhal E, Nûmeãková A, and Kouba M. 2003. Palaeopathology of lufaa and other persons found beside his Shaft Tomb at Abusir (Egypt). Intern J Osteoarch 13:331-338.

Todd TW. 1920. Age change in pubis bone I.Amer J Phys Anthrop 3: $285-334$.

Trotter M, and Gleser GC. 1952. Estimation of stature from long bones of American Whites and Negroes. Amer J Phys Anthrop N.S. I0:463-5I4.

Velemínsk` P. 1999. Morfologické znaky na lidské kostfie (Morphological features on human skeleton) In: Stloukal M (edit.), Antropologie. Pfíruãka pro studium kostry (Anthropology. Manual for study of the skeleton). Praha: Národní muzeum, p 125-167.

Vlãek E. 1974. Anwendung von zwei Methoden der forensischen Medizin zur Altersbestimmung in der Paläoanthropologie. Anthrop Közlem 18:199-209. 